\title{
El proyecto intelectual de FLACSO-México, 1976-1984
}

\author{
The intellectual project of FLACSO-Mexico, 1976-1984
}

\section{Fernando Munguía Galeana}

FLACSO-México

Facultad de Ciencias Políticas y Sociales, FCPyS-UNAM

fmg.politicas@gmail.com

Resumen: El presente trabajo reflexiona sobre el proceso sociohistórico en el que se puede inscribir la fundación de la Facultad Latinoamericana de Ciencias Sociales (FLACSO) en México, en 1975, y la configuración del proyecto intelectual que la definirá en el ciclo 1976-1984. Como se discute en este documento, uno y otro, se articulan a partir de la idea del microclima intelectual en la que se conjugan y proyectan las tensiones y combates de una generación que traza un puente entre la impronta cientificista hacia el ejercicio crítico de las ciencias sociales en América Latina.

Palabras clave: Historia intelectual, FLACSOMéxico, sociohistoria, ciencias sociales; América Latina.

\begin{abstract}
This paper reflects on the sociohistorical process in which the foundation of the Latin American Faculty of Social Sciences (FLACSO) can be inscribed in Mexico, in 1975, and the configuration of the intellectual project that will define it in the 1976-1984 cycle. As discussed in this paper, one and the other, they are articulated from the idea of the intellectual microclimate in which the tensions and fights of a generation are conjugated and projected that draws a bridge between the scientific imprint and the critical exercise of sciences in Latin America.
\end{abstract}

Keywords: Intellectual history, FLACSO-Mexico, sociohistory, social sciences, Latin America. 


\section{Introducción}

El objetivo de este trabajo es analizar la configuración del proyecto intelectual fundacional de la Facultad Latinoamericana de Ciencias Sociales, sede académica México, en el periodo comprendido entre 1976 y 1984, registrando las derivas sociohistóricas que condujeron a su instalación en el país, mismas que corresponden a un plano de apertura de espacios institucionales en un contexto en el cual se registran diversos episodios en esa dirección. Sin embargo, para dimensionar la importancia que tuvo su apertura, resulta fundamental visibilizar la articulación de un grupo de intelectuales latinoamericanos que constituyeron la que denomino la matriz fundacional que, como discuto en el documento, resultó sustantiva para dotar de un horizonte intelectual y académico al proyecto de la Facultad durante este periodo. Dicha matriz o grupo, estará integrado por René Zavaleta, Juan Carlos Portantiero, Emilio de Ípola.

En conjunto, tanto la institución como este grupo fundacional, darán forma a lo que Dosse llamó como un "microclima intelectual" en el que se configuran una serie de intereses y posicionamientos que se corresponden a su vez con determinados combates intelectuales de la época, esto es, un ciclo en el que se ponen en tensión los alcances teóricos y metodológicos de las ciencias sociales críticas en América Latina. Hablo de un ciclo en la medida en que aparecen en él las tensiones entre perspectivas cientificistas y otros enfoques críticos que cruzan el conjunto de las disciplinas sociales en la región ya desde principios de la década de 1960 y que, para mediados de la siguiente, tendrán uno de sus momentos más acusantes, en el marco de la avanzada militarista y el obligado cierre de espacios de producción y difusión de pensamiento crítico en el Cono Sur.

\section{La configuración del microclima intelectual de FLACSO México}

El argumento que me interesa desarrollar es que en el vínculo que se conforma entre la planta docente que hará parte y el proyecto académico de la FLACSO-México que, como se verá responde también a diversas tendencias y disputas institucionales, tanto nacionales como internacionales, durante el periodo que se considera en este trabajo, se expresa una forma específica de configuración, un puente generacional e 
intelectual como lo planteo aquí, entre las ciencias sociales críticas que ya venían desarrollando desde la década de 1960 y que se alargarán hasta los primeros años de 1980, cuando se registra el inicio del proceso que ha sido denominado como de crisis de las ciencias sociales latinoamericanas, mismo que se agudizará con los efectos, susceptibles de ser considerados en sus determinaciones específicas de tiempo y lugar, que pudo tener el derrumbe del muro de Berlín, no ya como un acontecimiento aislado sino en una compleja urdimbre de ideas y producción de conocimiento científico que sirvió para delinear horizontes de transformación $\mathrm{y}$, a su vez, con las alternativas sociopolíticas y culturales que, en el caso mexicano, serán también elementos sustantivos para ese viraje académico.

Este quiebre marcará, justamente, el comienzo de un giro teórico, metodológico e institucional para el caso específico de FLACSO-México, pero cuyas consecuencias e impactos pueden identificarse en un espectro más amplio en la medida en que también es posible distinguir una transformación que alcanzará al campo intelectual latinoamericano -y el mexicano no será la excepción-, mediante la modificación en los contenidos de los planes de estudios, en los perfiles de proyectos de investigación impulsados y en los sentidos que desde entonces tendría la práctica de recepción, producción y difusión de conocimientos críticos en el conjunto de las ciencias sociales en la región.

La delimitación temporal que me interesa, responde también a que dicho ciclo es compartido entre un grupo de estudiantes y profesores cuyas preocupaciones intelectuales y académicas se pueden ubicar dentro de ese amplio crisol de pensamientos y enfoques críticos que se expondrán en los proyectos por desarrollar análisis de las condiciones estructurales y las coyunturas concretas de sus países mediante enfoques y perspectivas sociohistóricas que respondían a un intento, uno de los últimos de ese periodo, por dar cuenta de manera sustantiva del sentido de recepción y traducción de las ciencias sociales críticas latinoamericanas para esa generación (GIORDANO, 2014).

Esto se aprecia, como procuro mostrar más adelante, en las publicaciones y trabajos que unos y otros desarrollarán, ya sea mediante libros, publicaciones institucionales (documentos de trabajo), participaciones en eventos nacionales e internacionales, así como en la elaboración de tesis por parte de los alumnos y en la manera en como algunos de ellos se integrarán a la planta docente en los años 
posteriores a culminar sus estudios de la Maestría en Ciencias Sociales, el programa con el cual inician las actividades académicas en la Facultad.

Otro elemento importante para establecer este criterio temporal y sociohistórico, es que después de 1984 varios de los académicos e intelectuales que fueron centrales para articular y dar formar al proyecto de FLACSO-México vuelven a sus países, en el comienzo de las transiciones a la democracia en América del Sur o se integraran a los procesos políticos en Centro América; algunos otros, se vinculan de manera más directa en diversos espacios e instituciones académicas en México tales como la UNAM o El Colmex, o bien, como es el caso de Zavaleta, los alcanza la muerte. Es a partir de este momento, cuando marcadamente comienza internamente lo que se puede considerar como una suerte de "mexicanización" de la propia Facultad.

El antes y el después del ciclo que relevo en las páginas siguientes, por su parte, ha sido objeto de diversos trabajos encargados de reconstruir, con una perspectiva de mediana duración, las vicisitudes de las ciencias sociales en América Latina, unas veces en sus manifestaciones disciplinares o bien institucionales; otras, mediante la revisión de experiencias específicas como las publicaciones académicas o la formación de grupos específicos (BEIGEL, 2009; GIORDANO, 2014b).

Este encuentro tuvo lugar, a su vez, en un contexto sociohistórico local que será una especie de umbral en el que se conjugan la experiencia e intereses previos, materializados en forma de capital simbólico y cultural (BEIGEL, 2009), de un grupo de académicos que, desde distintas posiciones de influencia en el campo intelectual y académico, habían comenzado ya con la formación de espacios de investigación y docencia y cuya participación en las gestiones políticas y administrativas pero, sobre todo, en el funcionamiento inicial de la Facultad resultaría definitivo.

Hay que recordar que años antes, ya desde la década de 1950 se había dado un fuerte impulso a la fundación de este tipo de espacios como el Centro de Estudios Latinoamericanos (CELA) y el Centro de Estudios e Investigaciones Interdisciplinarias (CEIICH), en la UNAM; que se vigorizará en los años setenta con el Centro de Estudios Sociológicos (CES) del Colmex y la fundación de la Universidad Autónoma Metropolitana (UAM), en 1973 y 1974, respectivamente. Se trata, pues, de un "microclima" intelectual en el que madurarán intereses, perspectivas y enfoques analíticos detonados por el impacto de los acontecimientos históricos que les anteceden y que implican para ellos un cierto tipo de compromiso activo con los "combates de su tiempo" (DOSSE, 2006: 45-51). 
Es por ello que sugiero que en este ciclo se conjugan y se visibilizan diversos elementos estructurales y procesos sociales y culturales, en este caso intelectuales y académicos, que marcan la configuración específica del campo intelectual de las ciencias sociales latinoamericanas en el proyecto académico de FLACSO-México, cuya manifestación es clave para relevar los componentes del puente, sus cimientos estructurales, así como para distinguir el perfil de sus constructores y sus peatones, es decir, para ubicar a esos sujetos en el entramado de las relaciones y posiciones que ocuparán en las estructuras que los determinan en el sentido de visibilizar sus posibilidades e intervención en dicho campo y en sus vínculos con otros (BOURDIEU, 2002).

La idea del puente remite, sí, a una figura estructural que prevalecerá con el tiempo, pero sobre todo a la imagen del tránsito que no siempre ha de seguir una misma dirección, que se puede recorrer de ida y vuelta en un mismo movimiento o bien, que puede implicar momentos para detenerse a medio camino, para evaluar lo avanzado y que el posible destino sea también apreciado con otros sentidos. Quienes formaron parte de a la comunidad académica de FLACSO-México, con todas sus diferencias y 128 encuentros, son los protagonistas de esa historia intelectual.

\section{FLACSO-México en el crisol de las ciencias sociales latinoamericanas}

A partir de la visibilización de los vínculos intelectuales, políticos e ideológicos que se establecieron entre un grupo diverso y polifacético de científicos sociales latinoamericanos en el periodo que va de 1976 a 1984, teniendo como espacio de encuentro la sede mexicana de la Facultad Latinoamericana de Ciencias Sociales fundada un año antes, esta primera parte del documento reconstruye la historia de la fundación de la institución poniendo especial énfasis en el lugar que ocupó en el mapa académico mexicano que se configuró, a su vez, como una expresión singular e importante en el crisol de las ciencias sociales de la región.

No propongo trazar otra lectura sobre la historia intelectual de los exilios que forzaron la movilidad de esa pléyade de cientistas sociales latinoamericanos, tema respecto al cual, por lo demás, aunque como se ha señalado no se haya investigado todavía en toda la "espesura" que merecería y queden muchas cosas que decir así como líneas que explorar, se puede sugerir que, sobretodo en los años recientes, se ha 
avanzado en un tratamiento cada vez más riguroso (YANKELEVICH, 2010; GILLIER, 2016), sino señalar algunos elementos sobre la emergencia de una generación crítica de intelectuales cuyo encuentro en la FLACSO-México ocurre en un pasaje fundamental que indicará una transformación radical en las formas de ejercicio de las mismas ciencias sociales en México y en diversos países de la región.

Hay un elemento, entonces, de transmisión de ideas y de configuración intelectual que es puesto en tensión en este ciclo, que va más allá de la proximidad física pero que, al mismo tiempo, se proyecta hacia otros espacios, una vez que los miembros de ese grupo, tanto la planta docente como los estudiantes del ciclo de interés, regresan a sus países o se insertan de manera diferenciada a la institucionalidad universitaria.

En este sentido, resulta singular que en las reconstrucciones de los exilios intelectuales o de las condiciones de producción y difusión de los discursos académicos y teóricos de la época, prácticamente nada se haya discutido sobre el trabajo de quienes hicieron parte de la fundación y primeras generaciones de profesores y alumnos de la Facultad Latinoamericana de Ciencias Sociales fundada en México en 1975 y que comenzó sus actividades docentes y de investigación al año siguiente.

Así, cuando se analiza el arribo de exiliados latinoamericanos y su presencia en la academia mexicana, se suele relevar la impronta que dejaron en instituciones como la UNAM, la UAM, El Colegio de México, el INAH, el CIDE, entre otras. Posiblemente por una cuestión meramente cuantitativa, por ejemplo, Pablo Yankelevich, en su trabajo sobre los exilios argentinos en México, no releva información relativa a aquellos académicos que ocuparon un espacio laboral en FLACSO, como sí hace con las instituciones antes señaladas (YANKELEVICH, 2010).

En el contexto de la miríada de esos exilios latinoamericanos (Argentina; Bolivia; Brasil; Chile; Uruguay), y durante el gobierno de Luis Echeverría (1970-1976) que desplegó esa política de puertas abiertas a los perseguidos políticos de la región pero que hacia las organizaciones populares y líderes de izquierda nacionales tuvo responsabilidad específica en actos de represión -por ejemplo, la masacre de estudiantes en 1968 y la guerra sucia durante los setentas-, es necesario volver sobre esa historia para recomponer un episodio nodal en la dinámica general de los exilios intelectuales y el ciclo más amplio de los procesos de recepción y difusión de perspectivas críticas en las ciencias sociales que, en pocos años, modificaron de manera sustantiva los ámbitos institucionales de la academia mexicana. 
Desde este enfoque, también se logran distinguir las matrices y las trayectorias teóricas y conceptuales, los trabajos específicos y las investigaciones que en cada uno de esos espacios se comenzaron a abrir, tanto de los académicos cuyas carreras pueden considerarse como consolidadas, y en las cuales tuvo una impronta destacada el pensamiento crítico que se ubica de manera clara dentro del amplio y complejo archipiélago de los marxismos, pero también entre aquellos jóvenes que, cursando en esos años sus estudios de maestría, en el caso específico de FLACSO, en los que incorporan algunos elementos de esa herencia crítica, formarán después parte de una siguiente generación que ya en la década siguiente experimentarán la crisis de las ciencias sociales latinoamericanas (SOSA, 1994; KIM PARK, 1996). Serán ellos los que en buena medida tendrán que cruzar el puente intelectual que se construye en la propia Facultad y del cual ellos mismos ayudarán a forjar los cimientos.

Por tanto, en ese encuentro entre lo general y lo específico, y con el énfasis puesto en la articulación de la dimensión intelectual y política de los espacios académicos, FLACSO-México aparece en un sitio y en un momento de apertura de una época que habría de revolucionar el conjunto de las ciencias sociales en México y en América Latina. Se trata de un espacio que sirve de puerta de entrada para estos perseguidos políticos, condición que en buena medida fue posible dando su vinculación con la Organización de Naciones Unidas y, que para entonces estaba inserta en un proceso de internacionalización que fue a su vez una estrategia de sobrevivencia ante la ola represiva de las dictaduras, en el cual las más diversas perspectivas críticas tendrán cabida y proyección (STAVENHAGEN, 2015).

Desde su fundación en 1957 la FLACSO, con auspicio de la UNESCO, hizo parte del proyecto de regionalizar y ampliar los estudios y análisis sobre las condiciones de "atraso" de América Latina, disputando las visiones teóricas y enfoques metodológicos predominantes, mismos que en su mayoría provenían de las ciencias sociales norteamericanas, y que dieron forma al tipo de ciencias sociales con marcado interés cuantitativo con el supuesto ánimo de fortalecer su cientificidad. Al respecto, Rodolfo Stavenhagen apuntó que,

Hasta el primer quinquenio de los sesenta, predominaron - sin contrapeso en el plano conceptual- el funcionalismo estructural parsoniano y las teorías de alcance medio de Robert Merton, así como las técnicas de encuesta (survey) en el plano metodológico. Teoría y metodología se 
combinaban armónicamente con los instrumentos que en esa época proporcionaba la estadística (STAVENHAGEN, 2015: 182).

Según destaca Pérez Brignoli, el respaldo de la UNESCO duró hasta 1969 y fue entonces cuando el gobierno chileno asumió un rol trascendental para asegurar la continuidad académica de FLACSO, primero, durante el último periodo del gobierno de Eduardo Frei y, en seguida, con Salvador Allende hasta el golpe militar de 1973 (PÉREZ BRIGNOLI, 2008). Si bien el autor subraya esta condición como el inicio de una fase de "crisis y transición" en la medida en que se puso en riesgo su estabilidad institucional y financiero, puede sugerirse que fue también el periodo de mayor vinculación y producción intelectual en la medida en que se ampliaron los horizontes institucionales y se fortalecieron los lazos de solidaridad e intercambio entre académicos de distintos países. Así, desde inicios de los setenta, además de Chile, se irán perfilando programas y sedes de la FLACSO en Panamá, Cuba, Argentina, Ecuador y México.

En esos mismos años resulta sintomático que se promoviera, por la vía de la Alianza para el Progreso, una contraofensiva ideológica con repercusiones en el campo de las ciencias sociales. El influjo de las perspectivas estructural funcionalistas y de sistemas, así como la sociología científica predominantes en ese contexto, constituían los principales derroteros de la producción en ciencias sociales en la región y, también, en la FLACSO (PÉREZ BRIGNOLI, 2008). El trayecto, por tanto, estuvo acompañado de diversas disputas que se dieron en el seno de la UNESCO y la CEPAL y que se trasladarían hacia el entorno más inmediato de la Facultad, pero que tendencialmente abrieron un camino hacia la latinoamericanización de los debates al interior de esos organismos y para la posibilidad de que, mediante la intervención del gobierno chileno, FLACSO se consolidara en aquel país hasta el derrocamiento del gobierno de la Unidad Popular, en 1973.

Así, desde la CEPAL, en un inicio, se comenzaron a gestar los primeros pasos para independizar la producción científica latinoamericana, pero fue sobretodo desde mediados de la década de 1960 que se logró materializar ese proyecto en diversos países de la región (STAVENHAGEN, 2015). Como en otros aspectos de la cultura, la política y la ideología, el impacto de la Revolución Cubana y los diversos movimientos de resistencia que le siguieron, la academia latinoamericana muy pronto hizo también parte de aquella nueva cartografía de pensamientos críticos que se comenzó a configurar. 
Cuando en 1967 se funda el Consejo Latinoamericano de Ciencias Sociales (CLACSO) con sede en Buenos Aires, la ciudad de Santiago de Chile, en donde se instaló originalmente la FLACSO, se había convertido ya en un importante centro académico de la época en el que la constante y rápida conformación de instituciones cobijó a diversos científicos sociales (BEIGEL, 2009, STAVENHAGEN, 2015), algunos de los cuales ya comenzaban su diáspora de exilios como los brasileños Theotonio dos Santos, Vania Bambirra, Ruy Mauro Marini-, que promovieron el paso definitivo del cientificismo imperante -funcionalismo, positivismo, empirismo-, hacia enfoques que desde la sociología y la economía, principalmente, proponían un análisis histórico y estructural de la región, "traduciendo" diversos elementos de la crítica de la economía política para dichos estudios, tal como quedó de manifiesto con la Teoría de la dependencia.

A partir de entonces, tanto el Consejo como la Facultad compartirán enfoques y perspectivas científicas y críticas que serán sustantivas para la configuración de un cierto tipo de "pensamiento renovador de izquierda" (KIM PARK, 1996), mismo que habrá de tener diversas fases en un lapso relativamente breve. En su trabajo Kim Park (1996) hace énfasis en que dicho núcleo estuvo sobretodo concentrado en la FLACSO Chile, previo al golpe de Estado de septiembre de 1973. Sin embargo, con los datos referidos por Stavenhagen (2014), se puede tener un panorama más integral del proceso y sugerir que, en efecto, se trató de una suerte de red de apoyos institucionales a través de los cuales fueron transitando académicos, proyectos de investigación, enfoques y problemáticas.

Si el núcleo sustantivo de dicha renovación puede encontrarse en el cruce entre esas dos instituciones hasta 1973, y entre Chile y Argentina como los países que abrieron espacios para fomentar y fortalecer el trabajo de ambas instituciones, será después en México en donde ese proyecto de renovación no solo encontrará los medios propicios para continuar el itinerario ya trazado con anterioridad, sino que ante la nueva condición de exilio y, en buena medida también de derrota política y estratégica, se darán a la tarea de radicalizar y profundizar en muchas dimensiones los contornos de la crítica científica antes imaginados.

Es en esta configuración un tanto abigarrada, tomando en préstamo una idea zavaletiana, en donde la historia de la fundación de la sede académica de la FLACSO en México cobra importancia. Si bien ésta queda documentada en algunos trabajos y los motivos políticos e institucionales se comprenden en el contexto referido antes, resulta 
más compleja la recuperación de la trayectoria intelectual de los exiliados latinoamericanos y de los académicos mexicanos que participaron en las actividades de docencia e investigación durante sus años iniciales, por lo que se trata de un proyecto que apenas puede quedar en un nivel indiciario.

Empero, con los registros disponibles que dan cuenta de los cursos, seminarios o talleres dictados, o de las publicaciones individuales y colectivas, y la información también puede rastrearse en los acervos de tesis (vinculando autores, temas y direcciones), con las pistas dejadas con las publicaciones editadas por la misma Facultad en esos años e, incluso, en algunos materiales audiovisuales de homenajes posteriores es posible recomponer algunos pasajes del proceso y sugerir algunas hipótesis sobre la configuración del proyecto intelectual de la Facultad. Otros registros, de tipo secundario, están en forma de huellas ubicadas en artículos y libros que tratan temas paralelos, como los exilios o las actividades editoriales y de divulgación de algunos de los involucrados (BURGOS, 2004; YANKELEVICH, 2009; CORTÉS, 2015).

Quedan de manifiesto algunos indicios sobre la vitalidad intelectual y la impronta de la Facultad para la ampliación del espectro científico en toda la región, incluyendo el Caribe. En principio, puede reconocerse ${ }^{1}$ el grupo fundacional que se constituye en torno a René Zavaleta Mercado que fue el "director-fundador" de la sede, desde 1975 a 1980 y, profesor desde 1976 hasta el ciclo académico de 1982-1984. De ese grupo harían parte también Juan Carlos Portantiero, Emilio de Ípola. Otros, como Fernando Cortés, José Luis Nájenson, Pablo González Casanova, Atilio Borón, Francisco Zapata, Carlos Pereyra, Agustín Cueva, Susana Bruna, Ciro Cardoso, Adolfo Sánchez Vázquez y el mismo José Aricó, entre otros muchos, fueron profesores invitados y permanentes durante estos años. ${ }^{2}$

Así, cuando en 1976 llegan a México José María Aricó y Juan Carlos Portantiero, cuya salida de Argentina se ve forzada por el golpe militar de ese año pero

\footnotetext{
${ }^{1}$ Esa sugerencia se observa en la relación que guardan estos intelectuales con los procesos de titulación, mismos que se desprenden de los registros de tesis de las primeras generaciones (1978-1980; 1980-1982) de la Maestría en Ciencias Sociales, disponibles en la Biblioteca René Zavaleta, de la FLACSO y las trabajos que fueron publicados por la misma Facultad en su colección de Documentos de trabajo. No se encontró el programa de la primera promoción, 1976-1978.

${ }^{2}$ El dato es recuperado del discurso pronunciado por Francisco Valdés en 2017, con motivo de la reinaguración de la Biblioteca de la FLACSO, con el nombre de René Zavaleta Mercado. Disponible en: https://www.youtube.com/watch?v=jXPV8nmWqyU

También, en la intervención del mismo Francisco Valdés, la conmemoración del XXXVIII aniversario de la FLACSO-México, en 2014. Dispoible en: https://www.youtube.com/watch?v=lV 7a77ZkPw
} 
que ya desde 1974 habían sufrido distintos tipos de persecución, encontrándose obligados a terminar con la edición de Pasado y Presente, por ejemplo (CORTÉS, 2015), comienzan a trabajar casi de inmediato en la FLACSO.

Portantiero, por su parte, tendrá un espacio docente y académico sustantivo a la Facultad, impartiendo clases, participando en dirección de tesis de las primeras generaciones de estudiantes de la maestría y publicando, como parte de la serie "Documentos de trabajo" de la Facultad, algunos textos fundamentales de su propia producción intelectual y que serán decisivos en la lectura y recepción del pensamiento gramsciano de la época. Entre los más importantes de esos textos están: “Gramsci y el análisis de coyuntura (algunas notas)" de 1979 y "Sociedad civil, Estado y sistema político", en 1982. La que con seguridad puede considerarse como su contribución más importante a las ciencias sociales latinoamericanas y a los debates teóricos que en esos mismos años se daban en otras latitudes, Los usos de Gramsci, fue publicada por vez primera en 1977 en México y, según el testimonio de Fernando Cortés, fue en FLACSO en donde se afinó la última revisión del texto. ${ }^{3}$

En tanto, José María Aricó también impartió clases, pero no figura registro de él como director de tesis o publicaciones suyas por parte de la Facultad ${ }^{4}$. En cambio, más conocida es su prolija actividad editorial durante su exilio en México, vinculándose prontamente con la editorial Siglo XXI para continuar con la edición de los Cuadernos de Pasado y Presente y para hacerse cargo de la Biblioteca del Pensamiento Socialista, siendo ese un espacio de difusión fundamental para la edición y publicación de diversos materiales en los que se recoge la producción intelectual de diversos miembros tanto de la Facultad como de otras instituciones mexicanas. ${ }^{5}$ De Emilio de Ípola, sabemos que

\footnotetext{
${ }^{3}$ Raúl Burgos data, basándose en una entrevista posterior a Portantiero, que "el cuerpo fundamental de ese texto" estaba concluido en 1975 y que la primera edición se publicó en los Cuadernos de Pasado y Presente, (que ya entonces coordinaba Aricó en la editorial Siglo XXI) y una segunda edición en 1981, también en México, por la editorial Folios (BURGOS, 2004: 229 y 239).

${ }^{4}$ De la actividad docente de Aricó en México hubo que esperar casi treinta y cinco años para conocer los cursos que dictó en 1977 en el Colegio de México, y que finalmente aparecieron con el título de Nueve lecciones sobre economía política en el Marxismo. Cfr. José Aricó, Nueve lecciones sobre economía política en el marxismo. México, El Colegio de México, 2011.

${ }^{5}$ Es bien conocida la importancia de la editorial Siglo XXI en la producción y difusión de pensamientos críticos y del impulso que proveyó a las ciencias sociales latinoamericanas. Entre el basto catálogo de publicaciones que se impulsaron en esos años de la configuración del proyecto intelectual de Flacso, por ejemplo, podrían destacarse dos títulos, coordinados por Julio Labastida Martín del Campo, claramente conectados entre sí por las temáticas y preocupaciones intelectuales que se recogen en ellos; el primero, Hegemonía y alternativas políticas en América Latina que recoge las participaciones de diversos intelectuales que participaron en el seminario del mismo nombre, en la ciudad de Morelia, en 1980. El segundo, también producto de un seminario realizado en la ciudad de Oaxaca, Los nuevos procesos
} 
fue también en México donde se publicó por primera vez su trabajo Ideología y discurso populista, en 1982, por la editorial Folios, la misma que editó Los usos de Gramsci, y que reunía trabajos comprendidos entre 1973 y 1981, como él mismo consigna en la introducción.

Con René Zavaleta como director de la Facultad a partir de 1976 y hasta 1980, antes de su paso por el Centro de Estudios Latinoamericanos (CELA) de la UNAM, según el testimonio de Francisco Valdés (2017), son invitados a impartir clases en FLACSO diversos cientistas mexicanos y latinoamericanos, entre ellos Pablo González Casanova, con el cual había entablado relación en la UNAM, y asume la responsabilidad de dictar los cursos de Teoría Sociológica y Problemas de la teoría del Estado en América Latina, además de que se vincula con el proceso de dirección de tesis de las primeras generaciones de estudiantes de la maestría y se encarga de otras tareas administrativas. Por otro lado, Zavaleta será quien más trabajos (libros y ensayos) publique durante su estancia en México y, si bien no todos fueron redactados originalmente aquí, sí es posible identificar que se trató de documentos que hicieron parte de su producción intelectual y docente, mucha de la cual se realizó justamente en la FLACSO.

Tabela 1: Obras de René Zavaleta publicadas en México en el periodo 1975-1984

\begin{tabular}{|l|l|l|}
\hline \multicolumn{1}{|c|}{ Obra } & Año & \multicolumn{1}{|c|}{ Fuente original } \\
\hline Clase y conocimiento & 1975 & $\begin{array}{l}\text { Historia y sociedad. Revista latinoamericana de } \\
\text { pensamiento marxista, segunda época, ed. Separata, } \\
\text { núm. 7: 3-8. }\end{array}$ \\
\hline $\begin{array}{l}\text { Luchas antiimperialistas en } \\
\text { América Latina }\end{array}$ & 1976 & Revista Mexicana de Sociología, vol. 38, núm. 1: 9-28. \\
\hline $\begin{array}{l}\text { El fascismo y la América } \\
\text { Latina }\end{array}$ & 1976 & Revista Nueva Política, núm. 1, enero-marzo: 1987-192. \\
\hline
\end{tabular}

sociales y la teoría política contemporánea. En el primero participan Emilio de Ípola, que escribe en coautoría con Liliana de Riz el texto de "Acerca de la hegemonía como producción histórica (apuntes para un debate sobre las alternativas políticas en América Latina)", y Juan Carlos Portantiero con el texto "Notas sobre crisis y producción de acción hegemónica". Para el libro del seminario de Oaxaca, De Ípola y Portantiero escriben juntos un ensayo que se volverá sustantivo para los debates de la teoría política latinoamericana, titulado "Lo nacional popular y los populismos realmente existentes"; además, René Zavaleta también participa con uno de sus trabajos célebres de la época "Cuatro conceptos sobre la democracia”. José Aricó, por su parte, prologó el libro de Hegemonía y ahí dejó constancia del horizonte por el que atravesaban las ciencias sociales latinoamericanas y, justamente, de los combates intelectuales que ellas y ellos asumían como generación: "Medirnos con las preguntas de nuestro tiempo implica poner a prueba los principios mismos de una teoría que no admitió nunca, ni aquí ni en parte alguna, una ‘traducción' puntual” (ARICÓ, 1985: 16). 


\begin{tabular}{|c|c|c|}
\hline $\begin{array}{l}\text { Consideraciones generales } \\
\text { sobre la historia de Bolivia } \\
(1932-1971)\end{array}$ & 1977 & $\begin{array}{l}\text { González Casanova, P. (coord), América Latina. } \\
\text { Historia de medio siglo, vol. 1, México, Siglo XXI, pp. } \\
\text { 74-128. }\end{array}$ \\
\hline $\begin{array}{l}\text { Las formaciones aparentes en } \\
\text { Marx }\end{array}$ & 1978 & $\begin{array}{l}\text { Historia y sociedad. Revista latinoamericana de } \\
\text { pensamiento marxista, núm. } 18 \text {, verano: } 3-27 \text {. } \\
\text { (Se publicó también como folleto en FLACSO-México } \\
\text { en 1979) }\end{array}$ \\
\hline $\begin{array}{l}\text { Cuatro conceptos de la } \\
\text { democracia }\end{array}$ & 1982 & Revista Dialéctica, año 7, núm. 12, septiembre: 11-30. \\
\hline El Estado en América Latina & 1983 & Revista Ensayos, núm. 1, primer trimestre: 45-64. \\
\hline Las masas en noviembre & 1983 & $\begin{array}{l}\text { Zavaleta Mercado, R. (comp.), Bolivia, hoy, México, } \\
\text { Siglo XXI, pp. 11-59. }\end{array}$ \\
\hline $\begin{array}{l}\text { Forma clase y forma } \\
\text { multitud }\end{array}$ & 1983 & $\begin{array}{l}\text { Zavaleta Mercado, R. (comp.), Bolivia, hoy, México, } \\
\text { Siglo XXI, pp. 219-240. }\end{array}$ \\
\hline $\begin{array}{l}\text { Lo nacional-popular en } \\
\text { Bolivia }\end{array}$ & $\begin{array}{l}1984 \\
(1986)\end{array}$ & $\begin{array}{l}\text { Zavaleta Mercado, R. Lo nacional popular, México, } \\
\text { Siglo XXI. }\end{array}$ \\
\hline
\end{tabular}

Fuente: Elaboración propia.

De manera específica, este grupo va a desarrollar una serie de problematizaciones sobre la realidad latinoamericana desde una perspectiva que se define como "pluralista", en la que consideran una serie de contenidos de la teoría política, la sociológica clásica y diversas perspectivas contemporáneas, en las que destacan la recuperación de vertientes y matrices del pensamiento marxista, así como un énfasis en la reflexión desde el pensamiento social latinoamericano que dotarán de un perfil académico e intelectual específico a la FLACSO-México (FLACSO-1978).

Desde la idea de campo intelectual, se podría sugerir que en parte esas discusiones académicas se conectan y entran en sintonía con otras instituciones y expresiones político-intelectuales del contexto, en las que tendrán también alguna participación, como por ejemplo las diversas editoriales y revistas de análisis político de izquierda que circularon en esos años -Era; Siglo XXI, Grijalbo, Folios entre las editoriales; Historia y Sociedad, 1965-1981; Cuadernos Políticos, 1974-1990; Coyoacán, 1977-1985, las revistas (Illades, 2012)-, y que se extenderá casi a lo largo de todo el ciclo de la presencia de este grupo nodal de la Facultad, hasta 1984.

Tabela 2: Planta docente FLACSO-México, 1976-1984

Periodo
Permanentes
Invitados 


\begin{tabular}{|c|c|c|}
\hline 1976-1978* & $\begin{array}{l}\text { René Zavaleta } \\
\text { Juan Carlos Portantiero } \\
\text { Emilio de Ípola } \\
\text { Rodolfo Stavenhagen } \\
\text { Fernando Cortés } \\
\text { José Aricó } \\
\text { Pablo González Casanova } \\
\text { Atilio Borón } \\
\text { Ernesto López } \\
\text { José Luis Nájenson } \\
\text { Daniel Etcheverry } \\
\text { Alfredo Monza } \\
\text { Jorge Padua }\end{array}$ & $\begin{array}{l}\text { Manuel Camacho } \\
\text { Susana Bruna } \\
\text { Suana Mayo } \\
\text { Mabel Puccini } \\
\text { Gerard Pierre-Charles } \\
\text { Leopoldo Zea } \\
\text { José Luis Reyna } \\
\text { Francisco Zapata } \\
\text { René Mayorga } \\
\text { Carlos Pereyra } \\
\text { Agustín Cueva } \\
\text { Ciro Cardoso } \\
\text { Adolfo Sánchez Vázquez }\end{array}$ \\
\hline 1978-1980 & $\begin{array}{l}\text { René Zavaleta } \\
\text { Juan Carlos Portantiero } \\
\text { Emilio de Ípola } \\
\text { Susana Buna } \\
\text { Mabel Piccini } \\
\text { Alfredo Monza } \\
\text { José Luis Nájenson } \\
\text { Sonia Bengoechea } \\
\text { Atilio Borón } \\
\text { Fernando Cortés } \\
\text { Darío Braun } \\
\text { Daniel Etcheverry } \\
\text { René Mayorga } \\
\text { Ernesto López }\end{array}$ & $\begin{array}{l}\text { Adolfo Sánchez Vázquez (Teoría política } \\
\text { II. Teoría política marxista) }\end{array}$ \\
\hline 1980-1982 & $\begin{array}{l}\text { Juan Carlos Portantiero } \\
\text { Emilio de Ípola } \\
\text { Susana Buna } \\
\text { Sabine Manigat } \\
\text { Manuel Coello } \\
\text { Roger Bartra } \\
\text { José Luis Nájenson } \\
\text { Sonia Bengoechea } \\
\text { Fernando Cortés } \\
\text { René Mayorga } \\
\text { Ernesto López } \\
\text { Rafael Menjivar } \\
\text { Horst Grebe } \\
\text { Jorge Landinelli } \\
\text { César Verduga }\end{array}$ & $\begin{array}{l}\text { Sergio Zermeño } \\
\text { (Área social México) } \\
\text { José Nún } \\
\text { (Teoría de la estructura social) } \\
\text { Yuriria Iturriaga } \\
\text { (Lecturas dirigidas. Clásicos teoría política) }\end{array}$ \\
\hline 1982-1984 & $\begin{array}{l}\text { René Zavaleta } \\
\text { Juan Carlos Portantiero } \\
\text { Emilio de Ípola } \\
\text { Susana Buna } \\
\text { Sabine Manigat } \\
\text { Manuel Coello } \\
\text { Roger Bartra } \\
\text { José Luis Nájenson } \\
\text { Sonia Bengoechea } \\
\text { Fernando Cortés } \\
\text { René Mayorga } \\
\text { Ernesto López } \\
\text { Horst Grebe }\end{array}$ & \\
\hline
\end{tabular}




\section{Jorge Landinelli \\ José Nún \\ Giovanna Valenti \\ José Luis Reina \\ Pablo Maríñez \\ Alberto Arnaud}

Fuente: Elaboración propia con información tomada de los programas de la Maestría en Ciencias

Sociales, FLACSO-México, disponibles en la Biblioteca René Zavaleta.

\section{Consideraciones finales: combates de una época en redefinición}

Hasta ahora no se ha avanzado en la ubicación del lugar intelectual que tuvo la Facultad Latinoamericana de Ciencias Sociales en México. Las breves reflexiones que se delinean en este trabajo, como mencioné antes, son apenas indiciarias, pero quieren señalar la pertinencia de volver sobre esa historia intelectual con el objeto de entender también las diversas espesuras y conexiones que ha tenido la institución en el conjunto del campo académico mexicano desde su fundación y hasta el presente.

Para el ciclo relevado en este trabajo, se puede sugerir que se dio forma a un proyecto intelectual, apoyado sustantivamente sobre la importancia y el prestigio institucional que traía consigo la Facultad y, a partir del cual se configuró una red cuyos nodos entretejieron las trayectorias intelectuales y políticas de los científicos sociales que comenzaron a llegar a México hacia finales de 1960 y en los años posteriores, algunos expresamente para dar forma al proyecto académico de la FLACSO-México, pero también los estudiantes que comenzarán aquí sus estudios de posgrado y, para los cuales, la recién fundada Facultad representó una oportunidad singular para la profundización en el conocimiento de sus propios países y para la posibilidad de entrar en contacto con colegas cuyas preocupaciones intelectuales quedarán registradas en las temáticas y en los enfoques teóricos y metodológicos abordados en sus trabajos recepcionales para obtener el grado. ${ }^{6}$

Esta misma premisa quedó plasmada de esa manera en la carta que René Zavaleta, en su condición de director de la Facultad, dirigió a los estudiantes de la segunda promoción, en la que escribe:

\footnotetext{
${ }^{6}$ Entre 1976 y 1984 fueron presentadas 171 tesis para optar por el grado de Maestro en Ciencias Sociales, en la Facultad Latinoamericana de Ciencias Sociales.
} 
En la actual situación de la América Latina es un especial privilegio el que puedan realizarse estudios financiados en un nivel que es modesto, pero suficiente, en el ramo de las ciencias sociales. No es una exageración decir que en estos cursos se encuentran los representantes de una generación entera de cientistas sociales. Ello debe ser entendido también, tanto por los profesores como por ustedes mismos, como la construcción intelectual de tal generación (FLACSO-MÉXICO, 1978).

El apunte de Zavaleta es precisamente una de las huellas que, desde la perspectiva de la historia intelectual y el enfoque sociohistórico que animan este trabajo, aportan el indicio del valor que tuvo para aquel grupo la recepción, producción y difusión de conocimientos críticos que permitirán, en un contexto marcado por el ascenso y descenso de proyectos políticos revolucionarios y de crisis políticas desatadas por el autoritarismo militar que azotó al Cono Sur, volver a plantearse preguntas sustantivas sobre la historia de la región así como de las condiciones y alternativas políticas de su presente y, desde ahí, reemprender la construcción de esa pretendida generación crítica de científicos sociales. Como he querido mostrar, fue en intento por visibilizar aquél horizonte de posibilidad del que resultó también la constitución de ese microclima intelectual capaz de replantearse y redefinir los combates de una época específica.

Figura 1: Primera generación de la FLACSO México, 1976 


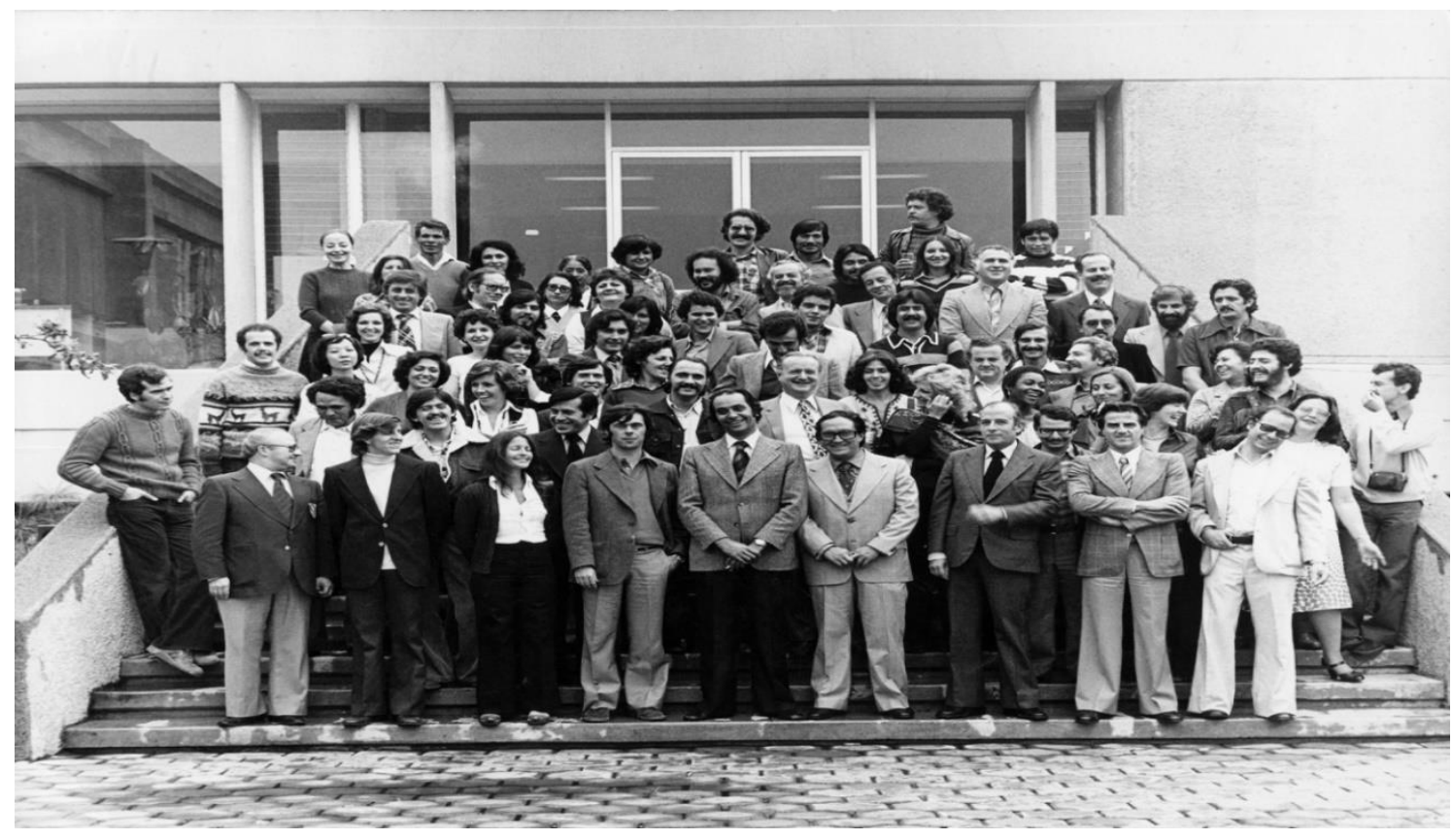

Fuente: Imagen disponible en el acervo de la Biblioteca René Zavaleta, FLACSO-México. Del grupo fundacional, se observa a Emilio de Ípola; Juan Carlos Portantiero y Rene Zavaleta, cuarto, quinto y sexto, respectivamente, también de izquierda a derecha, en la primera línea. Fernando Cortés se ubica en el extremo derecho superior y José Luis Nájenson es el primero, de izquierda a derecha, en la primera línea. En la fotografía también aparecen: Pablo González Casanova, José María Aricó, Agustín Cueva,

Francisco Zapata, Atilio Borón, Sabine Manigat, Susana Bruna, Jorge Landinelli, René Mayorga, Luciano Concheiro, entre otros.

\section{Referencias bibliográficas}

ARICÓ, José (1985). Hegemonía y alternativas políticas en América Latina. Prólogo. Ciudad de México: Siglo XXI Editores, pp. 11-16.

. (2011). Nueve lecciones sobre economía política en el marxismo. Ciudad de México: El Colegio de México.

BEIGEL, Fernanda (2009). La FLACSO chilena y la regionalización de las ciencias sociales en América Latina (1957-1973). Revista Mexicana de Sociología, 71, No. 2, abril-junio, pp. 319-349.

BOURDIEU, Pierre (2002). Campo de poder, campo intelectual. Tucumán: Editorial Montressor.

BURGOS, Raúl (2004). Los gramscianos argentinos. Cultura y política en la experiencia de Pasado y Presente. Buenos Aires: Siglo XXI Editores.

CORTÉS, Martín (2015). Un nuevo marxismo para América Latina. Buenos Aires, Siglo XXI Editores.

DE ÍPOLA, Emilio (1982). Ideología y discurso populista. Ciudad de México: Folios ediciones.

DOSSE, Francois (2007). La marcha de las ideas. Valencia: Universitat de València.

FLACSO-México (1978). Plan de estudios de la Maestría en Ciencias Sociales. México, FLACSO-México. 
GILLER, Diego (2016). La revista de la derrota. Exilio y democracia en Controversia (1979-1981). Latinoamérica, No. 63, México, UNAM, pp.37-64.

GIORDANO, Verónica (2014). ¿Qué hay de sociología histórica en la sociología crítica latinoamericana? Revista de la Red Intercátedras de Historia de América Latina Contemporánea, Segunda Época, Red Intercátedras de Historia de América Latina Contemporánea (RIHALC), No. 4, pp. 14-29. Disponible en http://publicaciones.ffyh.unc.edu.ar/index.php/RIHALC.

. (2014b). La sociología histórica y la sociología latinoamericana. La comparación en nuestras ciencias sociales. Revista de la Red Intercátedras de Historia de América Latina Contemporánea (Segunda Época), Año 1, No. 1, Córdoba, junio.

LABASTIDA MARTÍN DEL CAMPO, Julio (coord.) (1985). Hegemonía y alternativas políticas en América Latina. Ciudad de México: Siglo XXI Editores. (coord.) (1986). Los nuevos procesos sociales y la teoría política contemporánea. Ciudad de México: Siglo XXI Editores.

PÉREZ BRIGNOLI, Héctor (2008). Los 50 [cincuenta] años de FLACSO: desarrollo de las Ciencias Sociales en América Latina. San José: Editorial Juricentro.

SOSA, Raquel (1994). Evolución de las ciencias sociales en América Latina (19731992). Estudios Latinoamericanos, Vol. 1, No. 1, enero-junio, pp., 7-24.

STAVENGAHEN, Rodolfo (2015). FLACSO, CLACSO y la búsqueda de una sociología latinoamericana. Revista Perfiles Latinoamericanos, vol., 23, núm., 45, enero-junio, México, FLACSO, pp. 181-202.

YANKELEVICH, Pablo (2011). Ráfagas de un exilio. Argentinos en México, 19741983. Ciudad de México: El Colegio de México.

Artigo recebido em 12 de novembro de 2019.

Aprovado em 30 de novembro de 2019.

DOI:10.12957/intellectus.2019.47131 